\title{
Correlation Between Low Back Pain Among Medical Students and Prolonged Unhealthy Sitting with E-learning During COVID-19 Pandemic
}

\author{
Mahmoud H. El-Bidawy ${ }^{1,2}$, Rakan Algahtani ${ }^{3 *}$, Moataz Daadour ${ }^{3}$, Tariq Alanazi ${ }^{3}$, Abdulrahman Albedaiwi ${ }^{3}$, Abdulrahman Ben Mozan ${ }^{3}$ \\ ${ }^{1}$ College of Medicine, Department of Basic Medical Science, Prince Sattam Ibn Abdulaziz University, Al-Kharj, Saudi Arabia \\ ${ }^{2}$ Faculty of Medicine, Physiology Department, Cairo University, Cairo, Egypt \\ ${ }^{3}$ College of Medicine, Prince Sattam Ibn Abdulaziz University, Al-Kharj, Saudi Arabia \\ Correspondence should be addressed to Rakan Algahtani; College of Medicine, Prince Sattam Ibn Abdulaziz University, Al-Kharj, \\ Saudi Arabia, Email: rakan3wad@gmail.com
}

Received: 28 August 2021, Revised: 18 September 2021, Accepted: 1 October 2021, Published: 7 October 2021

Copyright (C) 2021 El-Bidawy et al. This is an open access article distributed under the Creative Commons Attribution License, which permits unrestricted use, distribution, and reproduction in any medium, provided the original work is properly cited.

\begin{abstract}
Background: During the Covid-19 pandemic, Saudi Arabia instructed all institutions to deliver online educational activities. Distance e-learning emerged as an alternative to traditional education. E-learning involves long hours of sitting which can lead to postural problems and a series of health issues, including low back pain among medical students. This study is aimed to identify the correlation between low back pain and prolonged sitting during e-learning during the COVID-19 pandemic among medical students in Prince Sattam Ibn Abdulaziz University at Al-Kharj, Saudi Arabia.

Methods: This is a cross-sectional survey study that was conducted in the medical college at Al-Kharj, Saudi. The selfadministered structured online questionnaire consisted of 25 questions. The survey consisted of four parts including a consent page, demographic data, history of low back pain and patterns and attitude of participant's towards devices and positioning during the process.

Results: A total of 188 participants were enrolled in the study showing that $39.7 \%$ of medical students at the university experienced low back pain during the e-learning period. The duration of pain was less than 30 minutes in $52 \%$ of the participants. The pain aggravated with prolonged sitting in $74.7 \%$ of the students and was relieved by rest in $8 \%$. We observed that $86.8 \%$ of the sample did not stretch in between lectures. However, correlation studies between low back pain, body mass index and exercise were non-significant.

Conclusions: The prevalence of LBP during e-learning among medical students was $39.7 \%$. However, there was no significant risk factors that affected the occurrence of low back pain. This research should be expanded to other Saudi medical schools to get a broader assessment.
\end{abstract}

Keywords: low back pain, e-learning, medical students, COVID-19 pandemic, unhealthy sitting. 


\section{Journal of Healthcare Sciences}

\section{Introduction}

During the Covid-19 pandemic, Saudi Arabia instructed all institutions to deliver online educational activities. Distance e-learning emerged as an alternative to traditional education that needed students to attend classes on campus. E-learning involves prolonged sitting that can lead to postural problems and a series of health issues, including low back pain (LBP) among medical students. Low back pain is a common disorder affecting nearly everyone at some point. For most people affected by low back pain, substantial pain or disability is short-lived, and they soon resume normal activities, regardless of advice or treatment received (1).

According to the World Health Organization (WHO), low back pain is a risk factor for disability in adults of all ages. A study found the following risk factors associated with low back pain: age; obesity, psychosocial factors, including anxiety and depression; occupational factors; decreased flexibility; mobility of muscles; hypermobility; postural habits; level of physical activity; daily fun activities, such as watching TV and computers (2). There is a strong relationship between chronic low back pain and incorrect, prolonged sitting positions (3). Low back pain is one of the most troublesome complaints among students. A review of 9 studies showed that the prevalence of chronic low back pain was $3.9 \%-10.2 \%$ (4). Some studies reported a high prevalence of lower back pain among medical students, possibly due to unhealthy sitting positions assumed while studying. The medical syllabus requires a lot of time and effort, given that medical students study for 5-8 hours per day (on average) (3-5). Several studies have evaluated LBP and its relation to medical students. A study (published on August 30,2014) was conducted on 125 medical residents (out of a total population of 194) at the Imam Reza Hospital, Tabriz University of Medical Sciences showed that the prevalence of low back pain in medical residents was reported to be as high as $76.9 \%$ in female and $45.2 \%$ in males (6). Another study (published in 2019) assessed the prevalence of low back pain in correlation with epidemiological and postural habits among 629 Brazilian medical students. Results showed that most medical students had LBP, being more common in females and associated with postural habits. Depression and anxiety are linked to the disability caused by LBP in this population (7). This study assessed the impact of policies used to control the Covid-19 pandemic, such as changing the learning method from traditional education in a learning institution to virtual online courses (distance e-learning) from home and discontinuing physical activities, on LBP among medical students. Distance e-learning involves prolonged sitting without a change in position for an extended period, which may cause passive stiffness in the lumbar spine and increase the risk of low back pain (8). A sedentary lifestyle potentially raises the possibility of recurrent low back pain. (9) These effects can worsen with incorrect posture and decreased physical activity among medical students. This study assessed the impact of these factors on lower back pain and its relationship to posture in medical students.

This study aimed to estimate the impact of virtual classes and the need to attend these classes through laptops or other devices on the increased sitting time of medical students. Specifically, we intended to identify the correlation between low back pain among medical students at Prince Sattam Ibn Abdulaziz University (PSAU), Al-Kharj, and prolonged incorrect postural habits adopted while attending virtual classes during the Covid-19 pandemic, as instructed by the Saudi Ministry of Health to control the pandemic in the Kingdom. Further, we intend to assess the prevalence of low back pain among male adult medical students at PSAU (who live in Riyadh and Al-Kharj) during distance learning and its relation to factors such as sitting position while attending virtual classes, stretching exercises in-between classes, the scheduling of breaks between classes, and body mass index (BMI). Finally, not many studies have discussed the adverse effects of E-learning.

\section{Methodology}

This is a cross-sectional survey study that utilized a preverified questionnaire. A stratified random sample was taken from the male medical students from the first year to the fifth year of the College of Medicine at Prince Sattam Ibn Abdulaziz University (PSAU) at Al-Kharj, Saudi Arabia. According to the Raosoft online sample size calculator, the minimum recommended sample size for the study was 136 participants. The inclusion criteria were undergraduate medical students in Prince Sattam Ibn Abdulaziz University's medical college, those attending classes from home using distance learning methods and those who experienced low back pain during the e-learning period.

The questionnaire was distributed online among the students over a period of six weeks. The survey consisted of 22 
Journal of Healthcare Sciences

research questions with 12 closed ended, five dichotomous, two open-ended, one numerical rating scale, and two multiple selection questions. A pilot study was conducted, and the survey was validated using the Cronbach alpha index. The survey consisted of four parts. The first part consisted of obtaining participant consent while the second part included questions about the age, academic year, place of residence, history of chronic illnesses, history of known back disorders or previous back pain during e-learning. Afterwards, the third part was only for participants who experienced low back pain during e-learning to analyse pain, identify the cause, duration, aggravating factors, relieving factors, associated symptoms, radiating nature of pain, pain description, pain severity using a scoring system. The scoring scale started from zero, which indicates no pain, one to three points for mild pain, four to seven for moderate pain, and eight to ten for severe pain. Lastly, the fourth section was related to the study patterns of the participants during e-learning, such as devices used, position while attending classes, study time, any stretches performed between lectures, body weight, height, and exercise routine. Data management and statistical analysis were performed using the software suite IBM statistical Package for the Social Sciences Statistics (v27, SPSS Inc., Chicago, USA) and a clinical significance of $<0.05$ was deemed significant.

\section{Results}

A total of 189 students were enrolled in the study. We found that $39.7 \%$ of the study group experienced LBP during distance e-learning and the duration of pain was found less than 30 minutes in $52 \%$ of the students. The pain aggravated with prolonged sitting in $74.7 \%$ of students and was relieved by rest in $80 \%$. Moreover, $86.8 \%$ of students did not stretch in between lectures. As shown in Table 1 , the place of residence was mainly two cities, Riyadh and Al-Kharj. Half the students had a BMI with a mean value of $26.39 \pm 6.16$. Most participants did not complain of any chronic diseases and had no known back disorders. However, the prevalence of low back pain during e-learning was $39.7 \%$ and mainly workrelated, as mentioned in the survey (Table 1).

\section{Table 1: Characteristics of the study population}

$$
\text { Characteristics }
$$

$$
\text { N }
$$

\begin{tabular}{|c|c|c|}
\hline Characteristics & $\mathbf{N}$ & $\%$ \\
\hline \multicolumn{3}{|l|}{ Age } \\
\hline$<23$ & 60 & $31.7 \%$ \\
\hline$\geq 23$ & 129 & $68.3 \%$ \\
\hline \multicolumn{3}{|l|}{ Academic year } \\
\hline $1^{\mathrm{st}}$ & 43 & 22.8 \\
\hline $2^{\text {nd }}$ & 37 & $19.6 \%$ \\
\hline $3^{\text {rd }}$ & 29 & $15.3 \%$ \\
\hline $4^{\text {th }}$ & 42 & $22.2 \%$ \\
\hline $5^{\text {th }}$ & 37 & $19 \%$ \\
\hline \multicolumn{3}{|l|}{ Body Mass Index (BMI) } \\
\hline$\geq 25$ & 93 & $49.5 \%$ \\
\hline$<25$ & 95 & $50.5 \%$ \\
\hline Mean \pm Standard Deviation & \multicolumn{2}{|c|}{$26.39 \pm 6.16$} \\
\hline \multicolumn{3}{|l|}{ Place of residence } \\
\hline Al-Kharj & 103 & $43.9 \%$ \\
\hline Riyadh & 83 & $54.5 \%$ \\
\hline \multicolumn{3}{|l|}{ Chronic illness } \\
\hline Yes & 24 & $12.7 \%$ \\
\hline No & 165 & $87.3 \%$ \\
\hline \multicolumn{3}{|c|}{ Any known disorders of the back } \\
\hline Yes & 13 & $6.9 \%$ \\
\hline No & 176 & $93.1 \%$ \\
\hline \multicolumn{3}{|l|}{ Back pain during e-learning } \\
\hline Yes & 75 & $39.7 \%$ \\
\hline No & 114 & $60.3 \%$ \\
\hline \multicolumn{3}{|l|}{ Cause of pain } \\
\hline Accidents & 2 & $2.7 \%$ \\
\hline Sport & 8 & $10.7 \%$ \\
\hline Work-related & 57 & $76 \%$ \\
\hline Stress & 2 & $2.7 \%$ \\
\hline Others & 6 & $8 \%$ \\
\hline \multicolumn{3}{|l|}{ Duration of pain } \\
\hline $1-30 \mathrm{~min}$ & 39 & $52 \%$ \\
\hline 30 min-2 hours & 20 & $26.7 \%$ \\
\hline All day & 16 & $21.3 \%$ \\
\hline \multicolumn{3}{|l|}{ What increases the pain } \\
\hline Lifting heavy weights & 7 & $9.3 \%$ \\
\hline
\end{tabular}

\begin{tabular}{l|c|c|} 
Age & \multicolumn{2}{|c|}{} \\
\hline$<23$ & 60 & $31.7 \%$ \\
\hline$\geq 23$ & 129 & $68.3 \%$ \\
\hline
\end{tabular}


Journal of Healthcare Sciences

\begin{tabular}{|c|c|c|}
\hline Prolonged sitting & 56 & $74.7 \%$ \\
\hline Walking & 5 & $6.7 \%$ \\
\hline None & 2 & $2.7 \%$ \\
\hline Others & 5 & $6.7 \%$ \\
\hline \multicolumn{3}{|c|}{ What helps in decreasing the pain } \\
\hline Rest & 60 & $80 \%$ \\
\hline Analgesics & 10 & $13.3 \%$ \\
\hline None & 5 & $6.7 \%$ \\
\hline \multicolumn{3}{|l|}{ Associated symptoms } \\
\hline Nausea & 2 & $4 \%$ \\
\hline Vomiting & 1 & $1.3 \%$ \\
\hline Fever & 1 & $1.3 \%$ \\
\hline Headache & 11 & $14.7 \%$ \\
\hline No associated symptoms & 59 & $78.7 \%$ \\
\hline others & 4 & $5.3 \%$ \\
\hline \multicolumn{3}{|l|}{ Pain shifting } \\
\hline Not radiating & 55 & $73.3 \%$ \\
\hline Neck & 11 & $14.7 \%$ \\
\hline Shoulder & 4 & $5.3 \%$ \\
\hline Lower limb & 5 & $6.7 \%$ \\
\hline \multicolumn{3}{|c|}{ Decreased appetite along with the low back pain } \\
\hline Yes & 4 & $5.3 \%$ \\
\hline No & 71 & $94.7 \%$ \\
\hline \multicolumn{3}{|l|}{ Time spent in e-learning } \\
\hline $1-3$ hours & 25 & $13.2 \%$ \\
\hline
\end{tabular}

\begin{tabular}{|l|c|c|}
\hline 4-5 hours & 58 & $30.7 \%$ \\
\hline 6-7 hours & 66 & $34.9 \%$ \\
\hline 8-10 hours & 30 & $15.9 \%$ \\
\hline $11+$ hours & 10 & $5.3 \%$ \\
\hline Do you stretch between lectures? & & \\
\hline Yes & 25 & $13.2 \%$ \\
\hline No & 164 & $86.8 \%$ \\
\hline
\end{tabular}

According to the survey, $78.7 \%$ of the students had no associated symptoms with low back pain. The most common symptom among the students was headache (14.7\%), followed by nausea (4\%). Also, $1.3 \%$ of students complained of fever and vomiting, and 5.3\% had other symptoms (Figure 1). Chi-square test was used to assess the association between low back pain and time spent in e-learning. No statistically significant association was found between low back pain and the number of hours spent in E-learning, BMI or exercise (Table 2).

\begin{tabular}{|l|c|}
\hline \multicolumn{2}{|c|}{$\begin{array}{c}\text { Table 2: Association between LBP and time } \\
\text { spent in e-learning, and LBP and BMI }\end{array}$} \\
\hline \multicolumn{1}{|c|}{ Variable } & P-value \\
\hline LBP and time spent in e-learning & 0.39 \\
\hline LBP and BMI & 0.18 \\
\hline LBP and exercise & 0.63 \\
\hline
\end{tabular}

LBP: low back pain, BMI: body mass index

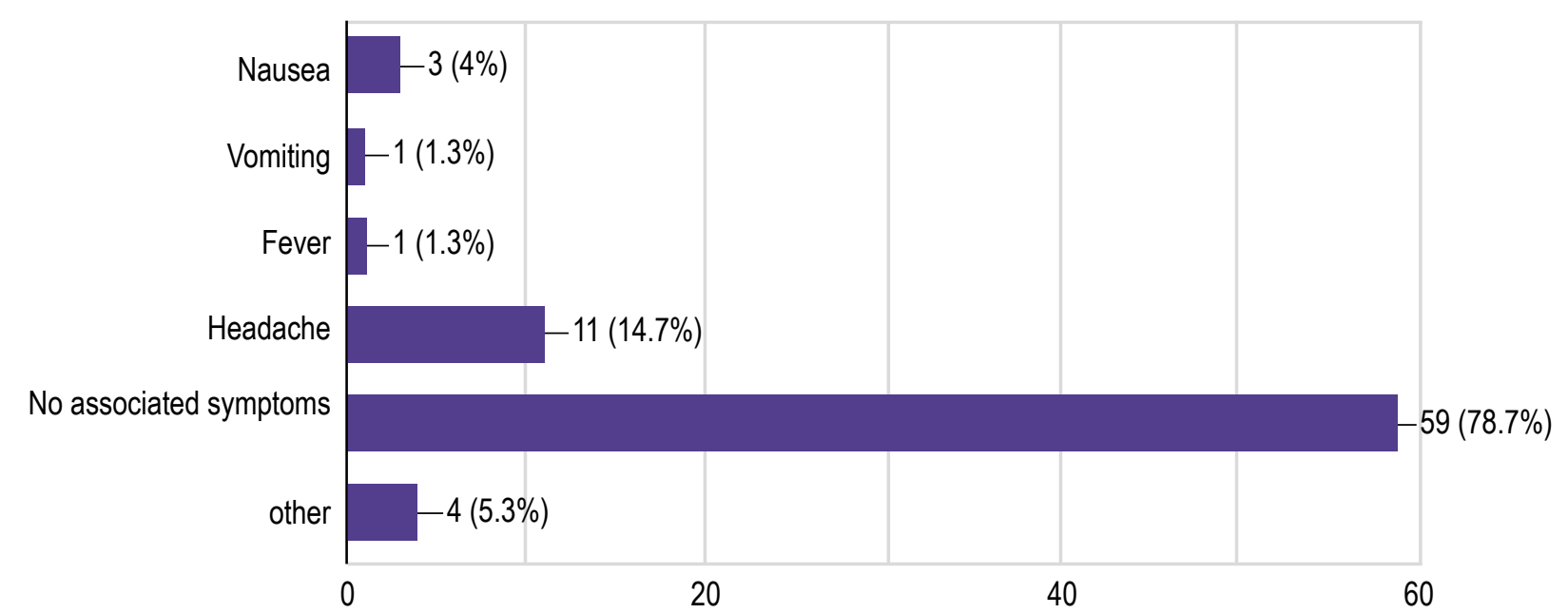

Figure 1. Symptoms associated with low back pain 


\section{Journal of Healthcare Sciences}

\section{Discussion}

In our study, most medical students had no known back disorders or chronic illnesses. However, about $39.7 \%$ of students complained of back pain, mostly related to work and study environment, during distance education. Most of our participants had no associated symptoms or radiating pain. Most students experienced mild to moderate pain that was compressing in nature. More than half of the students did not exercise or stretch between lectures. Moreover, sports were the second most common cause of LBP among medical students and $39.7 \%$ of our sample experienced LBP during the e-learning period. The duration of pain was less than 30 minutes in $52 \%$ of students. The pain aggravated with prolonged sitting in $74.7 \%$ of students and was relieved by rest in $80 \%$. Unfortunately, $86.8 \%$ of students did not stretch between lectures. Our results are consistent with a study by Citko et al. in 2018 where they reported that $41.54 \%$ of the medical staff complained of recurrent low back pain (4). Another study by Tavares et al. in 2018 showed no statistically significant differences between sitting hours and exercise with low back pain (2). Also, $94.4 \%$ of the medical residents participating in a study by Shams Vahdati et al. believed that lower back pain was work-related (6). Some studies reported a high prevalence of lower back pain among medical students, possibly due to unhealthy postural positions assumed by medical students while studying, given that the medical syllabus needs a lot of time and effort $(6,7)$. Another study states that a sedentary lifestyle potentially raises the possibility of recurrent low back pain (4). Beach et al. reported that prolonged sitting without change in position could cause passive stiffness in the lumbar spine, increasing the risk of low back pain (9). A cross-sectional study reported that the prevalence of lower back pain in medical residents was $76.9 \%$ in females and $45.2 \%$ in males (6). Another crosssectional study assessed the correlation between low back pain prevalence and epidemiological and postural habits among 629 Brazilian medical students showed a high prevalence of LBP in medical students, which was more common in females and associated with postural habits. Our study did not include psychological factors such as depression and anxiety. However, Tavares et al. found a link between anxiety/depression and disability caused by LBP (2). A review of 9 papers concluded that the prevalence of chronic low back pain was $3.9 \%-10.2 \%$ (10).

Limitation of our study include small sample size which is not reflective of the whole medical students population of Saudi Arabia. In addition, other factors were not explored such as psychological, social and tutor/teaching related. More studies are needed to further evaluate it.

\section{Conclusion}

The prevalence of LBP during e-learning among medical students in Al-Kharj was $39.7 \%$. No statistically significant association was found between low back pain and the number of hours spent in E-learning, BMI or exercise. More studies are warranted to explore low back pain prevalence among other universities in Saudi Arabia.

\section{Disclosure}

\section{Statement:}

The authors declare no conflict of interest.

\section{Funding:}

There has been no significant financial support for this work that could have influenced its outcome.

\section{Ethical Consideration:}

An analytical cross-sectional study was approved by The Research Ethics Committee in Prince Sattam Ibn Abdulaziz University, Al-Kharj, Saudi Arabia (approval No 56/2021).

\section{Data Availability:}

The survey used in this study is attached in the supplementary files in the paper.

\section{Author Contribution:}

All authors contributed to data collection, analysis, writing and drafting of the manuscript.

\section{References:}

1. National Collaborating Centre for Primary C. National Institute for Health and Clinical Excellence: Guidance. Low Back Pain: Early Management of Persistent Nonspecific Low Back Pain. London: Royal College of General Practitioners (UK) Copyright (C) 2009, Royal College of General Practitioners.; 2009.

2. Tavares C, Salvi CS, Nisihara R, Skare T. Low back pain in Brazilian medical students: a cross-sectional study in 629 individuals. Clinical rheumatology. 2019;38(3):939-42.

3. Bontrup C, Taylor WR, Fliesser M, Visscher R, Green $\mathrm{T}$, Wippert P-M, et al. Low back pain and its relationship with sitting behaviour among sedentary office workers. Applied Ergonomics. 2019;81:102894. 


\section{Journal of Healthcare Sciences}

4. Citko A, Górski S, Marcinowicz L, Górska A. Sedentary Lifestyle and Nonspecific Low Back Pain in Medical Personnel in North-East Poland. BioMed research international. 2018;2018:1965807.

5. Bin Abdulrahman KA, Khalaf AM, Bin Abbas FB, Alanazi OT. Study Habits of Highly Effective Medical Students. Adv Med Educ Pract. 2021;12:627-33.

6. Shams Vahdati S, Sarkhosh Khiavi R, Rajaei Ghafouri R, Adimi I. Evaluation of Prevalence of Low Back Pain Among Residents of Tabriz University of Medical Sciences in Relation with Their Position in Work. Turkish journal of emergency medicine. 2014;14(3):125-9.

7. Vujcic I, Stojilovic N, Dubljanin E, Ladjevic N, Ladjevic I, Sipetic-Grujicic S. Low Back Pain among Medical Students in Belgrade (Serbia): A Cross-Sectional Study. Pain research \& management. 2018;2018:8317906.
8. Smith DR, Wei N, Ishitake T, Wang R-S. Musculoskeletal disorders among Chinese medical students. The Kurume medical journal. 2005;52(4):139-46.

9. Beach TA, Parkinson RJ, Stothart JP, Callaghan JP. Effects of prolonged sitting on the passive flexion stiffness of the in vivo lumbar spine. The spine journal : official journal of the North American Spine Society. $2005 ; 5(2): 145-54$.

10. Meucci RD, Fassa AG, Faria NMX. Prevalence of chronic low back pain: systematic review. Rev Saude Publica. 2015;49:1-. 